\title{
Carolyn Merchant's View of Nature from the Perspective of Ecofeminism
}

\author{
LV Chun-hua ${ }^{1,2}$ WANG Zi-yan ${ }^{1 *}$ \\ 1. Faculty of Humanities and Social Sciences, Dalian University of Technology, alian, Liaoning Province, 116024; \\ 2. School of Philosophy and Law, Qiqihar University, Qiqihar, Heilongjiang Province, 161006
}

\begin{abstract}
This paper analyzes the Carolyn Merchant's ecofeminism perspective of nature. Merchant argues that there exists an artificially-constructed connection between nature and women. The root cause for which both nature and women are kept in subjection stems from the man-centered world outlook of "patriarchy". The upside of the statement still lies in the fact that Merchant conducts the analysis from the internal of "people" as a class-grouping to determine the original source of ecological problems from mankind itself. She deems that, through the efforts of human beings, the oppressive structure of human-to-nature and human relationships would be lifted, and thus a new equality can be hopefully brought within measurable distance of its establishment.
\end{abstract}

Keywords-Carolyn Merchant; Ecofeminism; View of nature; Metaphor

\section{INTRODUCTION}

The exploration of the root cause for which modern civilization contributes to environmental pollution and ecological imbalance has long been one of the themes of ecological philosophy. To address the issue, ecological philosophers differ in their answers. This difference originates from the different human cognitions of nature, or put it more accurately, different manners humans treat nature derive from different views of nature. Unlike mainstream ecological philosophers, ecofeminists observe the relationship between human and nature by introducing a gender perspective. Carolyn Merchant, as one of first representatives of the ecofeminism, analyzes the root cause of environmental crisis and forms one unique ecological feminist view of nature.

\section{II. "FEMALE” METAPHOR OF NATURE}

Carolyn Merchant's thoughts initiate from the exploration of the relationship between women and nature. So, what is nature? In the face of wayfaring seasons and multiplication of creations in nature, ancient human naturally "considered the world as an organism with its own life, saturated with divinity and keeping to continuous growth, from which everything in the world develops. The most primitive concept of 'nature' refers to growth as a process." [1] Marking a break with her traditional idea of examining the relationship between nature and "people"----the class-grouping considered as a whole, Merchant embarks from the internal of mankind and tried to locate its trace from the historical and cultural changes by closely linking sexes of human beings and nature together.
Through the interpretation of historical texts, Caroline Merchant has found that nature, in numerous cultural systems, is often metaphorized as a god of feminine, who appears as a mother-raiser. "Innana of Mesopotamians, Isis of Egyptians, Demeter and Gaia of Greeks, Geres of Romans as well as women images and myths of the European pagans, Asians, Latin Americans and Africans", [2] all of them are worships of the nature goddess in early human society. Archaeologically, late Paleolithic age and early Neolithic age were coincident within the period of matriarchal society, when both women and nature enjoyed high position, were closely connected and widely worshipped. The pervasive beliefs of nature gods and the female reproduction worship were a clear proof of it.

The image of the earth has been changing as has society. After matriarchal society graded to patriarchal society, women's position took a dive and gradually reduced to objects of male oppression. Likewise, the earth's image also changed imperceptibly. And after the scientific revolution in 16th and 17 th centuries, fundamental changes have taken place in the earth image. With the disappearance of mother-raiser image, another image, that is, wicked stepmother and the witch took the place. Going in hand with the birth of one view of nature, a value system to standardizing the behavior of human will usually take its shape correspondingly. Changes of nature view led to the changes of human's attitudes towards the earth, "the earth image as a raiser can be regarded as a cultural force, which limits, from the level of social morality, behavior types the human will select in relation to the earth; on the other hand, the new images of the rulers and the ruled have provided human's deprivation of nature with some cultural support." [3] 2Either traditional ethics or the natural blood ties restrict people not to act as they please to mother randomly, and even further, reverence and worship are required. But for the witch and the step mother image, the human are obliged to exercise control. Since nature is woman, the mankind's attitude towards woman is naturally projected parallel to nature. And such a transition to witch offers mankind the permit of the development of nature. Humans began to launch warfare to nature and attempted to meet the purposes of their own by applying technology to changing natural process to another track. The formerly obedient human in the presence of nature have become the tyranny of nature. Also, nature has transformed from a living organism into a silent and passive opposite existence outside the main, namely, "nature is dead". Dichotomy between human and nature produces an acceptable consequence of changes of the nature concept in the west. 
Through the scrutiny of the changes of metaphor of nature and their corresponding relationship with women in history, Carolyn Merchant has decided that the concept of nature and women turned out to be the result of man-made construction. 'Sex, gender or nature, has not any invariable 'essential' characteristics. For every individual, there appear many ideas and norms in the society of birth, socialization and education; it is to imbibe these ideas and norms that each forms some concept on nature together with other concepts on their relationship to nature. People in a designated period of time are always capable of constructing nature by attributing their life some significance. Elites or ordinary people, men or women, westerners or oriental, there is no exception." [2] Consequently, in Carolyn Merchant's beliefs, wanton mining and trample of nature have exerted a direct link to the reality of women's being oppressed.

\section{PHILOSOPHICAL ROOTS OF THE OPPRESSION OF NATURE AND WOMEN}

Woman images of nature have practically transited from a mother-raiser to subsequent disorderly witch images to be partitioned by others at will. So what constitutes the reasons for such a transition? Carolyn Merchant holds that the oppression of women and nature stems from the man-centered world outlook of "patriarchy". Based on the investigation to the modern science, Merchant insists that the contributions of those modern science founders, including Bacon, Descartes and Newton, etc. on human society be reassessed." Bacon as "father of modern science" has a famous saying that "science and technology can be paired off to nature, with nature as wife". And his potential ideas herein were evident of dual rule of science and technology over women and nature. In a society where men dominate main social labor, men as rule over women will be taken for granted. And when nature is metaphorized to women, "nature" as an analogue of women is governed by men as well. Just as "a woman's uterus succumbs to tweezers or scalpels from the sense of symbolism, uterus of nature wraps secrets which can be explored by means of technology; once finding these secrets, living conditions of mankind will be greatly improved." [5]By checking the process of the scientific revolution, Merchant found that there stands a reciprocal relationship between science and men. Scientific knowledge shares similar power, rationality and strength possessed by men. Confronted with domineering and masculine science, feminine nature has no choice but to accept being developed and ruled. It is due to alliance of patriarchal culture and modern science and the fact that the two unite together to practice the brutal domination and oppression over women and nature, and then the pair would be reduced to the object of being ruled, finally resulting in the "death of nature...". [2]

Patriarchal world outlook results in men's governance over both women and nature. However, the point is how the relationship between the ruling and the ruled is actualized? Having explored the root causes of all the associated oppressive systems, Carolyn Merchant's holds that such an establishment is originated from the subject-object dichotomy and the thinking mode of binary opposition in the western philosophy and culture. With the change in history, man and nature fall into dichotomy and binary opposition, during which human beings, from one part of nature, have become the external ruler of nature, while nature has reduced to into objective existence of human and become the other and object as well. Meanwhile, the same also happens to women under patriarchy. Consequently, Human's governance over nature and men's ruling of women has been legalized. To this point, Caroline Mercant holds a criticizing and negative attitude. She emphasized in the later works that "any analysis manifesting that women possess special nature and quality is practically targeted to bind women onto their biological fate, which will hinder the possibility of women's liberation, and the politics based on women's culture, experience and values can be regarded as a setback." [7]Since the shared root causes led to the oppression of women and nature, the fate of nature and that of women are inseparable. Only by uniting the two together more closely can they jointly break loose the shackles of patriarchal world. In other words, to liberate nature, we have to release women and then bring the great cause of the emancipation of nature and women into the common goal of mankind.

\section{Evaluation OF CAROLYN MERCANT'S ECOFEMINISM VIEW OF NATURE}

Carolyn Merchant's cognition of the ecological problems demonstrates her profound philosophical background and historical perspectives. She is apt to associate the ecological environmental problems with women's issues and then examine them in the greater historical setting. Focusing on digging deep historical origins, she attempts to provide the solution and the new methods to these problems finally. The uniqueness of her thoughts is embodied in several aspects as follows.

First of all, she holds that connection between women with nature is a kind of construction. Carolyn Merchant's, who is labeled as social ecofeminist, emphasizes more on the relationship between women and nature in sociological sense," the people living in a given period always construct nature by endowing lives with some meaning ".[2] Representative of mental ecofeminists Starhawk and Charlene Spretnak place more emphasis on the biological association between women and nature while Susan Griffin, a culture ecofeminist representative, affirms more the connection between the two. In "Woman and Nature: The Roaring Inside Her", she proposes "there stands a very intimate connection between women and the earth. Women reproduce offspring and the earth bears all things, so they share the experience. Women are the earth, and vice versa. Due to the particularity of women, they can better understand the nature. And nature talks to women just as nature does to itself, while women understand nature also like knowing themselves." [9] However, these views received harsh criticism from Carolyn Merchant, who claimed that the like theory can't extricate itself from logic contradictions so that they have committed a mistake of "essentialism" and dualism. In a certain sense, it is rational that Carolyn Merchant considers the relation between women and nature a non-biological characteristic. But seen from the cultural origin, since women can be closely linked with nature in history, the initial spontaneous contact should be based on the women's physiological and psychological characteristics. With the emergence of human cultural consciousness characteristics, it 
commenced to enjoy the possibility of active and voluntary cultural construction of nature, as is argued by Carolyn Merchant. According to Marxism, mankind is an existence of natural and social characteristics. These two get united in mankind as one class-grouping. Therefore, women-images of nature reflected in the historical discourse should also be based on both.

Secondly, she conducts analysis and adds criticism on modern scientific revolution and way of thinking of binary opposition in the west tradition, which is the root of the state of women and nature's being governed. She also examined evolution of nature in the historical setting of science, culture and economic systems; meanwhile, she weighs the nature from the static object to a living dynamic changing process. Nature in history has experienced a transition from an organic and vivid image to a silent and disorderly mechanical one. The very view of nature inspires us that nature possesses past and present. Certainly, it also has future, but the development totally depends on human behaviors. Only by reconsidering, amending and developing the value judgment of the scientific revolution, shifting the binary mode of thinking to the holism thinking, constantly adjusting the attitude and behaviors towards nature, mankind is likely to change from the other to the unity of man and nature as a whole. Carolyn Merchant's thoughts have also influenced a large number of scholars of cultural eco-feminism school in the late period. So they can not only focus on women's physical characteristics, but also show concerns for the change of social economic system. Through the attention of the cultural elements, they have offered comprehensive and multi-perspective thinking for the solution of the problem.

Finally, she identifies the significance of nature liberation with that of women liberation. This is one of inevitable logical conclusions drawn from Carolyn Merchant's thoughts. She pointed out in the preface of "The Death Of Nature" that "the linkage between women and nature has a long history, and their union has stubbornly persisted by means of culture, language and history."[2] Since the social role of women has constructive characteristics and the root cause is considered patriarchy and dualism, then the direction to addressing the issue has been pointed out. Modern system science has turned out that it is probable that human beings conduct concept innovation in view of science view and world outlook of reductionism. We can also construct a culture of gender equality and man-to-nature equality, in which the concerns for nature and for women can be well connected so as to help remove the oppression over women and nature, and this move, in a true sense, is the liberation of mankind itself.

\section{CONCLUSION}

To reflect upon the root of ecological crisis since the industrial society, the diagnosis mainstream ecologists determine is anthropocentrism, against which their prescription is eco-centrism. But eco-centralism theorists are always exploring the root cause and seeking the solution within the vision of the human-to-nature relationship. Their ethical dilemma lies in the fact that they unilaterally consider mankind an absolutely equivalent to all things in nature, overlooking that the root of the ecological problems is the crisis of human relations. Eco-feminists represented by Carolyn Merchant deeply analyze the inside of the class-grouping of human beings, although the conclusions can not be totally correct, they have opened up a brand new perspective and approach of study. To find the root cause of ecological problems from mankind itself, it is believed that, through the efforts of human beings, oppressive structures between human and nature as well as human relations will be lifted and the establishment of a new equality between man and nature, the relationship between people is just within measurable distance.

\section{REFERENCES}

[1] HE Huai-hong. Ecological Ethics-Mental resources and Philosophy Foundation [J]. Baoding: Hebei University Press, 2002:265. (In Chinese)

[2] Carolyn Merchant, Trans by Wu Guo-sheng. Death of Nature [M].Changchun:Jilin People's Publishing House, Preface, 2, Preface, 186-187, 38; 39, Preface, Introduction. (In Chinese)

[3] Carolyn Merchant.Radical Ecology:The Search for a Livable World [M]. New York: Routledge,1992.1.

[4] Griffin S. Woman and nature: The roaring inside her[M]. New York: Harper \& Row, 1978:104. 